\title{
Mobilidade transnacional, dissidência sexual e hibridismo em A confissão de Lúcio, de Mário de Sá- Carneiro (1914)
}

FERNANDO BELEZA

Newcastle University

\begin{abstract}
In this essay, I examine the uncanny in Mário de Sá-Carneiro's A confissão de Lúcio (1914). Drawing on Sigmund Freud, Julia Kristeva, and Homi Bhabha, I argue that the uncanny plays a crucial role in Sá-Carneiro's exploration of facets of both the queer experience and transnational mobility. On the one hand, it enables the destabilization of fixed gender identifications and the articulation of dissident sexual identities and politics. On the other hand, it brings into Sá-Carneiro's novella aspects of his own experience as an expatriate in the cosmopolitan urban space of Paris. Finally, Sá-Carneiro's embrace of the experience of the uncanny provides a point of departure to address hybridity within his broader literary production.
\end{abstract}

Keywords: Mário de Sá-Carneiro, modernism, uncanny, mobility, dissidence

Numa carta de Paris para Fernando Pessoa, datada de 13 de julho de 1914, véspera do Dia da Bastilha, Mário de Sá-Carneiro descreve uma sensação suscitada por um episódio ocorrido num passeio pelas ruas de Paris, durante as festas nacionais: 
Um tempo em extremo lepidóptero: calor (e ontem trovoada), mas sobretudo as impossíveis festas nacionais: balões, bailaricos, guitarras - como aí, tal e qual. Atravessando a rua Mazarine ontem eu e o Carlos Franco ficámos arrepiados, semi-loucos pois vimo-nos de súbito em pleno Bairro Alto. Simplesmente, concentrando melhor o nosso espírito, concluímos o nosso erro e sossegámos só porque não era o fado o que as guitarras raspavam.

(Em ouro 235)

O relato deste episódio, decorrido durante a segunda longa estadia do autor em Paris, lembra-nos de um procedimento recorrente na ficção de Sá-Carneiro: a afirmação de um temor súbito ("arrepiados, semi-loucos") que emerge a partir de uma determinada experiência, da chegada a um lugar particular, de uma visão ou encontro com uma figura peculiar. ${ }^{1}$ Neste caso, o temor emerge da extrema familiaridade, para ambos os expatriados portugueses, das comemorações nacionais francesas presenciadas nas ruas de Paris, que subitamente se confundem com o Bairro Alto lisboeta. Em nenhum outro texto de Sá-Carneiro este sentimento é evocado de forma tão frequente e com tantas implicações para a narrativa como em A confissão de Lúcio - a novela escrita em setembro de 1913, em Lisboa, mas moldada pela experiência da mobilidade transnacional vivida por Sá-Carneiro a partir do outono de 1912. Esta mobilidade emerge, através da vivência de Lúcio, como um dos motivos principais da narrativa. ${ }^{2}$

Lúcio, tal como Sá-Carneiro, é um jovem escritor português que fora para Paris para estudar Direito na Sorbonne. Na capital francesa, trava conhecimento com vários expatriados portugueses e, depois de alguma relutância inicial, começa a mover-se nos círculos artísticos da cidade, multiculturais e cosmopolitas. Este processo de pertença a uma comunidade de artistas e, de forma mais abrangente, à cultura modernista parisiense anterior à Grande Guerra são encenados pela participação de Lúcio numa festa organizada por uma

\footnotetext{
${ }^{1}$ Depois de uma primeira estadia em Paris, entre outubro de 1912 e junho de 1913, Sá-Carneiro regressou à capital francesa em junho de 1914 e ficou até pouco depois do início da I Guerra Mundial. Voltou, então, para Lisboa, passando uma temporada em Barcelona. Regressou uma última vez a Paris, em julho de 1915, onde acabaria por se suicidar no dia 26 de abril de 1916.

${ }^{2}$ Vários críticos têm feito referência à profunda ligação entre o autobiográfico e o ficcional em SáCarneiro (Martins). A manifestação da mobilidade transnacional em A confissão de Lúcio sublinha a relevância desta relação entre o autobiográfico e o ficcional em Sá-Carneiro.
} 
americana, lésbica e rica, que marca a primeira parte da novela (Park). A americana em conjunto com Gervásio Vila-Nova, um dos companheiros de Lúcio na cidade de Paris, são responsáveis por introduzir na narrativa formas de temor semelhantes àquela relatada na carta a Pessoa. Gervásio Vila-Nova é descrito como alguém que "perturbava," enquanto a americana fulva desperta "um medo semelhante ao que experimentamos em face do rosto dalguém que praticou uma acção monstruosa" (Sá-Carneiro, Verso e prosa 301). A segunda parte da narrativa é ocupada pela relação triangular entre Lúcio, Marta e Ricardo, que termina com a morte deste último e o suposto desaparecimento da figura estranha de Marta - a esposa enigmática que Ricardo trouxera de Paris, cuja verdadeira existência é sempre mantida em dúvida. Este receio particular revela-se ainda a partir de outros aspetos ao longo da narrativa: o surgimento de duplos (doppelgänger), a incerteza quanto à realidade de certas figuras, as referências ao "já-visto" (320) e a medos com origem na infância (322), etc. Este modo particular de temor súbito, pela forma como ele é experienciado pelas personagens da ficção de Sá-Carneiro em A confissão de Lúcio e pelo próprio na passagem da carta a Pessoa, pode considerar-se como uma manifestação do estranho, tal como este é comentado por Freud em Das Unheimliche (1919). ${ }^{3}$

A dificuldade de definir o estranho - enquanto forma específica do que evoca medo ou receio (Freud 123) —é um dos problemas que Freud e muitos outros teorizadores tiveram que enfrentar. Partindo dos significados particulares dos termos heimlich e unheimlich em alemão, Freud recusa a ideia-sugerida anteriormente por Ernst Jentsch—de que o estranho surge associado ao contacto com o novo/desconhecido (o não familiar [das Unheimliche]) e à incerteza intelectual em relação a algo ou alguém. ${ }^{4}$ Freud propõe, pelo contrário, que o estranho está ligado ao contacto com uma forma particular do familiar (das

\footnotetext{
3 À falta de melhor tradução para português, e seguindo o exemplo da Associação Portuguesa de Psicanálise, uso "o estranho" ao longo deste ensaio com o significado de das Unheimliche. Na secção em que Freud analisa o significado da palavra em várias línguas europeias, aponta o português e o italiano como línguas que usam perífrases para descrever a sensação do estranho. Infelizmente, não fornece qualquer uma dessas perífrases.

4 "For us the most interesting fact to emerge [...] is that among the various shades of meaning that are recorded for the word heimlich there is one in which it merges with its formal antonym, unheimlich, so that what is called heimlich becomes unheimlich [...]. This reminds us that this word heimlich is not unambiguous, but belongs to two sets of ideas, which are not mutually contradictory, but very different from each other - the one related to what is familiar and comfortable, the other to what is concealed and kept hidden. Unheimlich is the antonym of heimlich only in the latter's first sense, not in its second" (132).
} 
heimliche); nas suas palavras: "the uncanny is that species of the frightening that goes back to what was once well known and had long been familiar" (124). Procurando compreender o que pode tornar o familiar em algo que evoca o estranho, Freud conclui que esta forma de temor está relacionada com a emergência do que foi conhecido no passado e reprimido: algo um dia bem conhecido que deveria ter ficado escondido, mas acabou por ser trazido à superfície. O estranho para Freud está, assim, associado à dimensão incompleta do processo de repressão e surge, por exemplo, ligado ao complexo de castração, à evocação/emergência de crenças e/ou experiências infantis e ao contacto com formas não intencionais de repetição. A referência a estas formas não intencionais de repetição antecipa a elaboração do conceito de pulsão de morte em Jenseits des Lustprinzips (Além do princípio de prazer, 1920), que é responsável precisamente por formas obsessivas de repetição.

Em Das Unheimliche, Freud usa um episódio autobiográfico para descrever a forma como a repetição do mesmo pode evocar o estranho. Numa tarde quente de verão, Freud encontrava-se a passear pelas ruas de uma pequena cidade italiana:

I found myself in a district about whose character I could no longer remain in doubt. Only heavily made-up women were to be seen at the windows of the little houses, and I hastily left the narrow street at the next turning. However, after wandering about for some time without asking the way, I suddenly found myself back in the same street, where my presence began to attract attention. Once more I hurried away, only to return there again by a different route. I was now seized by a feeling that I can only describe as uncanny, and I was glad to find my way back to the piazza that I had recently left and refrain from any further voyages of discovery. (144)

Freud propõe, a partir da sua experiência, que "it is only the factor of unintended repetition that transforms what would otherwise seem quite harmless into something uncanny" (144). Este episódio narrado por Freud e as suas conclusões são particularmente sugestivos para compreender a evocação do estranho por parte de Sá-Carneiro, que também experienciou a estranha repetição não 
intencional do mesmo na rua Mazarine, em Paris. A cena presenciada por SáCarneiro e o seu companheiro, que deveria ser não familiar para os expatriados portugueses, revela-se familiar ao ponto de ambos não saberem se estavam em Lisboa ou em Paris, evocando, assim, o estranho que emerge da manifestação de formas não intencionais de repetição, comentado por Freud. $\mathrm{O}$ único elemento que surge como radicalmente distintivo é a ausência do fado, que marca a diferença-pondo fim à ideia de repetição—que sossega Sá-Carneiro e o assegura da distância entre o Bairro Alto e as festas nacionais na rua Mazarine, tornando claro o lugar onde estavam.

A forma como o estranho serve para iluminar a experiência parisiense de SáCarneiro, tal como é relatada na carta, remete-nos para o uso deste conceito no campo teórico em abordagens da experiência de mobilidade transnacional. Para Homi Bhabha, a experiência da quebra de fronteiras entre o familiar e o não familiar, que caracteriza o estranho, é típica da vivência do sujeito migrante e partilhada por todos que experienciam momentos de iniciação "extra-territorial and cross-cultural" (13). As experiências de mobilidade de Sá-Carneiro e Bhabha podem ser consideradas como privilegiadas, embora por razões diferentes. A estadia do português em Paris foi generosamente financiada pelo seu pai e, apesar de alguns problemas financeiros que se tornam mais prementes durante a última estadia em Paris (como revela a correspondência com Pessoa), teve a oportunidade de frequentar os cafés da cidade e viver confortavelmente. A abordagem de Bhabha à experiência migratória - apesar da diferença temporalé, também por isso mesmo, sugestiva para ler a correspondência, a poesia e a ficção de Sá-Carneiro, em especial para compreender a forma como a experiência de mobilidade transnacional e a vivência do estranho se manifestam na sua obra.

Bhabha usa a sua própria história de migração — que o levou desde a Índia até Boston, passando por Oxford, Brighton e Chicago-para discutir a experiência da mobilidade transnacional. As suas palavras servem para iluminar a sua e muitas outras vivências da mobilidade ao longo do século XX:

I have lived that moment of the scattering of the people that in other times and other places, in the nations of others, becomes a time of gathering. Gathering of exiles and émigrés and refugees; gathering on the edge of "foreign" cultures; gatherings at the frontiers; gatherings in the ghettos or cafés of city centers; 
gatherings in the half-life, half-light of foreign tongues, or in the uncanny fluency of another's language; gathering the memories of underdevelopment, of other worlds lived retroactively; gathering the past in a ritual of revival; gathering the present. (199)

Enquanto artista "exilado" no centro da modernidade europeia no início do século, Sá-Carneiro partilhou a experiência dos encontros nos cafés e dos passeios pelas avenidas com outros artistas portugueses. Apesar de alguma solidão (nessas mesmas avenidas e cafés onde escreveu a sua correspondência com Pessoa), cultivada pelo próprio como refere nas cartas, Sá-Carneiro compartiu as suas aspirações artísticas com outros modernistas, em particular com Santa-Rita Pintor, que de algum modo surge evocado na figura já referida de Gervásio Vila-Nova. ${ }^{5}$ Partilhou com eles uma ideia de afastamento da cultura portuguesa face aos modelos da modernidade europeia. Procurou e planeou modernizar a produção cultural portuguesa, especialmente nos seus projetos conjuntos com Pessoa (Beleza, "Orpheu cosmopolita"). Na sua vivência parisiense, como os sujeitos migrantes descritos por Bhabha, imitou, até certo ponto, o quotidiano no país de origem: "Cá vou passeando pelos boulevards como aí pelo Rocio e Rua do Ouro" (Em alma 33). Quando idêntica, esta repetição terá evocado o estranho, como aconteceu no episódio narrado na carta a Pessoa. Traduziu passagens de alguns dos seus textos para francês e chegou mesmo a fazer do ato de tradução um motivo literário com a invenção da obra de Zagoriansky que "traduziria" para português. Finalmente, apesar de tudo, Paris não foi sempre a cidade ideal com que Sá-Carneiro sonhara, como chega a comentar a Pessoa. ${ }^{6}$ A sua vivência em Paris foi também, para utilizar as palavras de Bhabha, uma "meia-vida" (199); numa carta de 15 de junho de 1914, descreve-se: "vivendo em verdade até hoje só em metade de mim" (Em ouro 208).

\footnotetext{
${ }^{5} \mathrm{O}$ relacionamento de Sá-Carneiro com Santa-Rita foi problemático, como mostram as suas cartas: "A minha convivência com o Santa-Rita prossegue quotidianamente, interessante, sem dúvida, mas por vezes m[ui] to fatigante" (Em ouro 50).

${ }^{6}$ Por exemplo, numa carta de 16 de novembro de 1912: "Não tenho de forma alguma passado feliz nesta terra ideal. Tenho mesmo vivido ultimamente alguns dos dias piores da minha vida" (SáCarneiro, Em ouro 40).
} 
A confissão de Lúcio é mencionada pela primeira vez numa carta para Pessoa de 21 de janeiro de 1913, o que mostra que os planos para a sua escrita datam da estadia de Sá-Carneiro em Paris. A novela, em conjunto com as cartas e a sua poesia, revela a importância da mobilidade de Sá-Carneiro para a modernização da produção literária portuguesa, fornecendo simultaneamente um relato ficcional do ambiente cosmopolita de Paris nos anos imediatamente anteriores à Grande Guerra e o seu contraste com a cidade de Lisboa nas margens do continente. Em particular, esta novela mostra como vários dos elementos inovadores da sua prosa estão relacionados com essa mesma experiência. Porém, o estranho em Sá-Carneiro não surge apenas ligado à contaminação da sua produção literária pela dimensão transnacional da sua vida. Partindo de uma leitura da construção do efeito do estranho em A confissão de Lúcio, argumentarei neste artigo que Sá-Carneiro, por um lado, abraçou a vivência do estranho que define a experiência da mobilidade transnacional e, por outro, recorreu a essa mesma categoria para afirmar, em A confissão de Lúcio, uma identidade sexual dissidente e uma pertença cosmopolita que ultrapassam as fronteiras familiares do nacional e os limites da heteronormatividade. Na novela em especial, a experiência de mobilidade transnacional ocupa um papel central e a vivência do cruzamento de fronteiras e da diferença, referidas por Bhabha, molda a narrativa, como se verá. No contexto do modernismo português, a experiência da mobilidade tem sido negligenciada pela crítica, especialmente em termos teóricos, apesar do interesse que o processo de deslocação territorial adquiriu nas últimas décadas em várias áreas. Persiste, entre a crítica académica em geral, uma certa ideia de que a mobilidade é uma questão contemporânea e menos um aspeto também definidor do modernismo do início do século e da modernidade em geral. De facto, o que tem sido escrito sobre a experiência da mobilidade transnacional é particularmente relevante para ler o modernismo português, especialmente as produções de artistas que, como Sá-Carneiro, tiveram a oportunidade de se movimentar para além das fronteiras nacionais.

A confissão voluntária feita por Lúcio de um crime que não cometeu-o assassinato de Ricardo - não cabe necessariamente na categoria de confissão de algo que deveria ter ficado escondido. Porém, esta confissão (enquanto tal) é apenas o pretexto para uma outra confissão: uma que nunca é categórica, mas que, apesar da incerteza, é sem dúvida sugerida. O que é confessado em $A$ confissão de Lúcio é o segredo do desejo entre Lúcio e Ricardo, como aliás a 
crítica tem mostrado de várias formas. Eduardo Pitta considera que "o cânone contemporâneo, português e homossexual, arranca com A confissão de Lúcio," embora, acrescenta, em 1914 esta não tenha podido "ser lida como devia" (12). ${ }^{7}$ A crítica que se lhe seguiu tem confirmado que a dissidência sexual se manifesta em A confissão de Lúcio de forma relevante no contexto português, emergindo de forma mais ou menos velada. Tem sido, por um lado, sublinhado o conflito entre desejo e proibição na novela e na obra de Sá-Carneiro (Arenas; PazosAlonso). Por outro lado, tem sido observada pela crítica a forma como o texto de Sá-Carneiro desconstrói formas fixas de género e sexualidade, seguindo um modelo de identidade sexual identificável com os discursos contemporâneos sobre a mesma (Amaral; Jones). Esta revisão recente da relevância do género e da sexualidade na obra de Sá-Carneiro tem, porém, sido feita muitas vezes de forma relativamente isolada em relação à leitura de outros aspetos da sua produção literária ligados ao contexto geográfico e cultural, embora, claro, reconhecendo por vezes a importância do ambiente da cidade de Paris para a construção do imaginário sexual e identitário no texto (Beleza, "Peripheral Desires;" Vasconcelos, "Painting the Nails").

Embora alguns dos elementos que permitem a elaboração do efeito do estranho na novela de Sá-Carneiro já tenham sido analisados pela crítica, nenhuma destas abordagens apresenta uma leitura abrangente da construção do estranho na sua obra e da sua relação com a política sexual do texto e a experiência da mobilidade transnacional. É precisamente no espaço de intersecção das abordagens de Freud, por um lado, e de Bhabha, por outro, que pretendo propor uma leitura de A confissão de Lúcio, que por sua vez permitirá trazer luz sobre a ética cosmopolita e o hibridismo que moldaram a produção literária de Sá-Carneiro. Nas páginas que se seguem, argumentarei que no caso de Sá-Carneiro há uma profunda continuidade entre dissidência sexual e a sua experiência transnacional, que se manifesta a partir de várias dimensões da construção do efeito do estranho em A confissão de Lúcio. Esta imbricação que emerge ao longo do texto entre a experiência de deslocação física, o cruzar de fronteiras entre Lisboa e Paris e a afirmação de uma política sexual dissidente tem sido até agora negligenciada pela crítica, apesar de, como procurarei mostrar

\footnotetext{
${ }^{7}$ Para uma reavaliação importante dos momentos iniciais deste cânone, ver Klobucka.
} 
neste artigo, essa continuidade e a sua relevância serem sugeridas pela novela e confirmadas pela poesia de Sá-Carneiro e pela sua correspondência com Pessoa.

\section{O estranho caso de Lúcio}

Freud comenta que na literatura há meios particulares para construir o efeito do estranho, que não existem no quotidiano familiar ao leitor. Alguns textos, embora possuam elementos que são tradicionalmente associados ao estranho, não despertam essa sensação. É o caso, como aponta, dos contos de fadas que, por se desviarem desde o início da realidade familiar ao leitor, tornam impossível a evocação do efeito do estranho. Pelo contrário, aqueles textos que prometem desde o início uma realidade quotidiana e acabam por ultrapassar as fronteiras desta facilmente permitem o acentuar do efeito do estranho em moldes que ultrapassam os do quotidiano (Freud 156-57). Este é precisamente o caso de $A$ confissão de Lúcio. Ao afirmar veementemente ao leitor que irá fornecer um relato fiel aos factos e depois indo muito para além do que acontece geralmente no quotidiano, o narrador/autor da confissão acentua o grau do estranho que várias das situações e personagens da novela envolvem. Para além deste aspeto, Sá-Carneiro inclui ainda uma outra forma de evocação do efeito do estranho que não é comentada por Freud, mas é decisiva na novela: através dos comentários de Lúcio sobre o temor causado por várias situações e personagens, Sá-Carneiro sublinha o efeito do estranho na narrativa, permitindo, simultaneamente, uma leitura baseada na subjetividade de Lúcio. Nas páginas que se seguem, centrarme-ei quer no estranho evocado por Lúcio quer nos elementos que permitem criar a sensação do estranho no leitor.

Como já referi, a evocação do estranho na novela inicia-se nas primeiras páginas com a socialização de Lúcio com Gervásio e, pouco depois, com a artista americana-que surge, desta forma, sem nome, apenas caracterizada pela nacionalidade e pelo facto de, tal como Lúcio, não ser originalmente de Paris. Ambas as personagens marcam aquela que é a primeira parte da narrativa, que termina com a "Orgia do fogo" e o estranho desaparecimento absoluto da americana (cujo destino o leitor nunca saberá). Gervásio Vila-Nova é uma figura que, nas sensações que provoca em Lúcio (a quem "perturbava"), segue o aspeto definidor do estranho, enquanto algo ligado ao que já fora familiar e foi reprimido. A origem desta sensação reside no facto de Gervásio evocar "cilícios, 
abstenções roxas" (299), isto é, formas de desejo não sancionadas pelos discursos normativos, trazendo assim à superfície do texto, desde o seu início, o que deveria ter sido mantido em silêncio. Para além disto, enquanto figura que evoca o estranho, Gervásio introduz no texto o motivo da mobilidade do reprimido entre os limites do inconsciente e o consciente, que, por envolver o cruzamento de fronteiras, mimetiza a sua mobilidade transnacional e a de várias das figuras que constituem os círculos artísticos descritos na novela. Antes de abandonar a narrativa, Gervásio é ainda responsável por introduzir uma outra figura: a americana fulva, que Lúcio conhece num contexto multicultural em que se juntam artistas "de todos os países" (301).

Tal como Vila-Nova, a americana desperta receio em Lúcio, que ele caracteriza como "um medo semelhante ao que experimentamos em face do rosto dalguém que praticou uma acção monstruosa" (301). Freud aponta as possíveis origens do sentimento do estranho nos casos em que surge associado a pessoas, casos que são particularmente sugestivos para a representação da americana na novela: "We can also call a living person uncanny [...] when we credit him with evil intent. But this alone is not enough: it must be added that this intent to harm us is realized with the help of special powers" (149). Lúcio, de facto, parece reconhecer poderes especiais à americana desde o momento que trava conhecimento com ela, acabando por confirmar essas suspeitas durante o espetáculo de music hall, em que a americana chega a parecer imune ao fogo: "E, outra vez desvendada - esbraseada e feroz, saltava agora por entre labaredas, rasgando-as: emaranhando, possuindo, todo o fogo bêbado que a cingia" (315). Para além de evocar receios infantis ligados a estes poderes extraordinários, enquanto figura estranha, a americana desperta ainda em Lúcio, tal como Gervásio fizera, o retorno de outros elementos reprimidos, ligados, no seu caso, à orientação sexual (referida por Gervásio) e uma vez mais associados ao cruzamento de fronteiras. No caso da americana, a sua nacionalidade é um dos poucos traços de identidade que conhecemos, para além do seu lesbianismo e das suas ideias sobre arte e desejo, expressas pela própria. Porém, ela é também por vezes identificada apenas como a "estrangeira" $(307,309)$, o que sublinha a importância deste aspeto em particular e, consequentemente, da noção implicada de cruzamento de fronteiras nacionais, que surge, desta forma, como processo análogo ao cruzamento/transgressão de fronteiras heteronormativas de género e sexualidade. 
A continuidade entre Gervásio e a americana no que diz respeito aos vários cruzamentos que as suas identidades envolvem é materializada através da sugestão do duplo. Neste caso, o duplo é formado por ambas as figuras:

Entretanto as cadeiras haviam-se deslocado e, agora, o escultor sentava-se junto da americana. Que belo grupo! Como os dois perfis se casavam bem na mesma sombra esbatidos - duas feras de amor, singulares, perturbadoras, evocando mordoradamente perfumes esfíngicos, luas amarelas, crepúsculos de roxidão. Beleza, perversidade, vício e doença. (305)

O surgimento do duplo é, para Freud, um dos motivos que mais fortemente produz o efeito do estranho (141). O duplo surge recorrentemente na novela de Sá-Carneiro e desperta esta sensação não apenas em Lúcio, mas também potencialmente no leitor, deixando ambos na incerteza sobre os limites/fronteiras que separam/delimitam alguma das personagens (em especial, Gervásio e a americana e a americana e Marta). Segundo Freud, "the uncanny quality [of the double] can surely derive only from the fact that the double is a creation that belongs to a primitive phase in our mental development" (143), evocando assim também o retorno do reprimido. Por um lado, o efeito do estranho sugerido pelas descrições/sensações de Lúcio, em que a experiência de mobilidade transnacional e o imaginário da dissidência sexual se cruzam, é confirmado pelo processo de duplicação que parece estar subjacente às representações de ambas as figuras. A constante articulação entre o cruzamento de fronteiras geográficas e a dissidência sexual, que irá continuar ao longo da narrativa e marcará também a figura de Marta, começa, desta forma, a emergir no texto enquanto aspeto central. Por outro lado, o duplo emerge no texto como elemento capaz de produzir no leitor o efeito do estranho, tornando a leitura da novela numa experiência potencial de retorno de reprimido, semelhante àquela vivida pelo autor da confissão, Lúcio.

A festa da americana emerge na narrativa como uma espécie de microcosmos da cidade cosmopolita de Paris dos anos que antecederam a Grande Guerra. Nas palavras do próprio Lúcio, o evento organizado pela americana junta uma "multidão bizarrada e esquisita" (310): 
Eram estranhas mulheres quase nuas nos seus trajes audaciosos de baile, e rostos suspeitos sobre as uníssonas e negras vestes masculinas de cerimónia. Havia russos hirsutos e fulvos, escandinavos suavemente louros, meridionais densos, crespos-e um chinês, um índio. Enfim, condensava-se ali bem o Paris cosmopolita—rastaquoère e genial. (310)

Os encontros dos migrantes à meia-luz, referidos por Bhabha, tomam a forma, nesta passagem da novela de Sá-Carneiro, de um grupo de convidados etnicamente diverso, uma multidão descrita como "bizarrada" e "esquisita." Por seu lado, a estranha fluência da língua do outro emerge da palavra "rastaquoère," que traz até ao nível do texto a dimensão multicultural da multidão e, claro, a importância do espaço parisiense para a constituição desta comunidade global de artistas. A presença de Lúcio na festa da americana, para além de possibilitar a construção de um episódio iniciático de pertença artística, surge também como um momento de afirmação de inclusão nessa comunidade cosmopolita e de valorização da experiência do estranho enquanto parte da vivência dessa mesma comunidade.

Equacionando a descoberta do inconsciente levada a cabo pela psicanálise com a descoberta de um outro em nós, um outro estranho, Julia Kristeva propõe que a psicanálise implica uma forma nova de cosmopolitismo. Trata-se de uma nova forma de solidariedade humana fundada na consciência da existência do inconsciente; por outras palavras, no reconhecimento do facto de que temos em nós toda a estranheza do outro. Nas suas palavras: "A ética da psicanálise implica uma política: tratar-se-ia de um cosmopolitismo de tipo novo que, transversal aos governos, às economias e aos mercados, trabalha para uma humanidade cuja solidariedade está fundada na consciência do seu inconsciente-desejante, destruidor, medroso, vazio, impossível” (202). Através da forma particular como a construção do efeito do estranho implica não apenas a encenação do retorno do reprimido, mas também o abraçar do estranho implicado na experiência da mobilidade transnacional e uma abertura radical ao outro, ao estrangeiro em nós, A confissão de Lúcio propõe a formulação de uma ética cosmopolita semelhante à descrita por Kristeva. No caso da produção literária de Sá-Carneiro, trata-se de uma posição ética cosmopolita em que a dissidência sexual e o processo de mobilidade transnacional se tornam indissociáveis. 
O espetáculo dado pela americana, que, nas suas palavras, é uma tentativa de "condensar" as suas "ideias sobre a voluptuosidade-arte" (310), é um dos momentos da construção do efeito do estranho em A confissão de Lúcio em que o leitor surge também implicado, através do estabelecimento de múltiplas possibilidades de leitura. Desde o primeiro momento em que Lúcio reentra na sala onde vai acontecer o espetáculo, ele confessa o impacto do efeito do estranho: "por mim, confesso, tive medo... recuei..." (311). A narração de Lúcio acaba mesmo por sugerir uma das principais conclusões de Freud, segundo a qual o estranho está ligado ao medo da castração. Ao referir-se à iluminação, Lúcio declara-se "impotente para a descrever" (311). A associação desta evocação do estranho ao complexo de castração torna-se ainda mais clara quando, um pouco mais à frente, Lúcio descreve a luz como "sexualizada" (312), tornando explícita a origem deste efeito do estranho. Por outro lado, a referência à luz elétrica e à sua contribuição para o efeito do estranho aponta para uma relação entre modernidade e o estranho em Sá-Carneiro; mais exatamente, entre a experiência da modernidade parisiense, dos seus espaços (teatros, festas, avenidas, cafés) e esta categoria particular de temor que acaba por moldar a sua obra.

No seu ensaio sobre o estranho, Freud argumenta que episódios de loucura e epilepsia são exemplos de atos que despertam esta sensação de temor; usando vários exemplos da literatura, propõe que o estranho suscitado pela loucura e epilepsia tem a mesma origem que o estranho provocado por pessoas a quem atribuímos más intenções e em quem reconhecemos poderes extraordinários (149). Esta parece ser a dupla origem do estranho evocado pelo espetáculo da americana, cujos movimentos no palco chegam mesmo a ser comparados com "estranhas epilepsias" (315), que, por sua vez, levam a um estado de perturbação geral na audiência: "A luz normal regressara. [...] Mulheres debatiam-se em ataques de histerismo; homens, de rostos congestionados, tinham gestos incoerentes" (315). Pazos-Alonso sugere que o episódio da "Orgia do fogo" é um dos vários exemplos nesta narrativa de uma expressão do desejo homoerótico latente através de mecanismos de "displacement and condensation." A sua abordagem do texto de Sá-Carneiro, à luz da interpretação dos sonhos freudiana, confirma a importância da encenação do retorno do reprimido para a construção 
da política sexual da novela. ${ }^{8}$ Igualmente relevante nesta passagem para a leitura que proponho é a construção do efeito do estranho em relação ao espaço da festa, para o qual viro agora a minha atenção.

Segundo Freud, um dos exemplos do que desperta o estranho é a visão dos órgãos genitais femininos, pela forma como evocam o complexo de castração. Seguindo esta proposta, a visão do "sexo áureo," neste momento da novela, pode ser lida como origem do receio de castração — reforçando a evocação deste complexo comentada anteriormente a propósito da iluminação-que se manifesta no terror descrito por Lúcio e posteriormente na desorientação sentida pelos convidados da festa e espetadores do espetáculo de music hall: "Então, numa última perversidade, de novo tomou os véus e se ocultou, deixando apenas nu o sexo áureo - terrível flor de carne a estrebuchar agonias magenta...” (314). Pretendo, porém, sugerir ainda uma outra leitura para esta passagem, mais sugestiva para o argumento em questão, recorrendo também ao ensaio de Freud. Este afirma que "neurotic men state that to them there is something uncanny about the female genitals" e que "what they find uncanny ['unhomely'] is actually the entrance to man's old 'home,' the place where everyone once lived" (151). A referência ao "sexo áureo," em conjunto com a arquitetura e o design do lugar da festa, como mostro de seguida, permitem ler o espaço cosmopolita parisiense como simultaneamente familiar e não familiar-estranho.

De facto, o estranho suscitado pela performance é acentuado pela representação do próprio lugar da festa da americana, comentado por Lúcio, que, em alguns aspetos, lembra um útero. Comentando a dimensão do estranho evocada pelo útero, Freud afirma: "Here too, then, the uncanny [the 'unhomely'] is what was once familiar ['homely', 'homey']" (151). Quando relata o efeito da luz elétrica no espaço da performance, Lúcio aponta para uma determinada sensação provocada que se aproxima do que podemos descrever como a vida intra-uterina: "nós respirávamos o estranho fluido" (311). Esta ideia de respirar através de um fluido lembra a experiência de um feto no útero, mais exatamente "the fantasy of living in the womb" que, como Freud argumenta, é um momento de desejo que desperta a sensação de estranho (150). Este é um "útero" profundamente multicultural e multiétnico, definindo o espaço cosmopolita de

${ }^{8}$ Pazos-Alonso refere, aliás, a relevância do ensaio de Freud sobre o estranho para ler a novela de Sá-Carneiro, em particular para abordar a figura de Marta, embora não chegue a aprofundar a sua análise nesse sentido (67). 
Paris como um lugar ao mesmo tempo familiar e não familiar: um lugar caracterizável pelo que podemos descrever como o estranho cosmopolita de SáCarneiro.

No episódio da festa da americana, há ainda uma outra camada que se prende precisamente com uma das formas de criação do estranho em Sá-Carneiro, abordada por Fernando Curopos. De acordo com Curopos, a figura da "estrangeira" possui referentes historicamente reais, que ele identifica no seu ensaio, em particular Natalie Barney e Loïe Fuller, entre outras. O que pretendo sugerir aqui é que mais importante do que estes referentes reais é a forma como a "estrangeira" surge como personagem que é ao mesmo tempo familiar e não familiar, reconhecível nos seus modelos históricos, mas demasiado desfamiliarizada para ser reduzível a qualquer um deles. Sá-Carneiro produz esta forma particular de estranho através da criação do que podemos considerar como um retrato compósito, em que se misturam vários referentes históricos na construção da figura ficcionalizada da americana. Ao mesmo tempo, a figura compósita da americana, tal como a novela de Sá-Carneiro, sugere que o estranho é, como argumenta Nicholas Royle (usando uma expressão de Shoshana Felman) um "reading effect": algo sempre aberto para ser relido, mas também sempre relido de forma diferente (8).

A expressão "retrato compósito" surgiu a partir de um tipo de imagem fotográfica experimental que se popularizou no século XIX, com uma forte influência no campo das ciências, em particular em vários ramos ligados à eugenia. A ideia e a prática do retrato compósito enquanto conjunto de retratos sobrepostos numa mesma placa fotográfica teve origem em Inglaterra com Francis Galton, primo de Charles Darwin e pioneiro na pesquisa eugénica. Galton procurou com esta prática desenvolver um método para sistematizar características típicas de certos desvios da norma humana, tais como o génio e a tendência hereditária para o crime. Ao sobrepor vários retratos de um sujeito, Galton e os praticantes que se seguiram pensaram conseguir identificar características próprias do génio ou de qualquer outro desvio. O resultado destes retratos compósitos era frequentemente uma imagem de um indivíduo que mantinha os traços e marcas supostamente essenciais do desvio, criando um indivíduo tipo. $\mathrm{O}$ uso desta forma de pensar a representação teve consequências artísticas e literárias, como mostra Max Saunders: "Whatever its shortcomings as science, and its susceptibility to eugenics or racist exploitation, composite 
portraiture of photography was a suggestive idea for artistic and literary notions of representation, and particularly for thinking about the relation between particularities and generalities, between individuals and types" (236). No caso concreto de A confissão de Lúcio, a utilização deste modo de construção permite criar um "reading effect" que é o efeito do estranho: a figura da americana (simultaneamente familiar, reconhecível, e não familiar), tal como a novela de Sá-Carneiro, são entidades sempre abertas para serem relidas mas também sempre relidas de forma diferente. ${ }^{9}$

Um outro exemplo do "reading effect" estabelecido pela novela surge com a figura de Marta. De todas as personagens de A confissão de Lúcio, nenhuma é tão estranha, quer aos olhos de Lúcio quer aos olhos do leitor, como a suposta amante de Lúcio. Rejeitando a afirmação de Pitta, segundo a qual A confissão de Lúcio não podia "ser lida como devia" em 1914 (12), recentemente argumentei que, para um leitor da época, Marta facilmente seria considerada como a materialização da alma de Ricardo, seguindo o modelo de identidade uranista, segundo o qual o desejo homossexual masculino estava associado à existência de uma alma feminina aprisionada num corpo masculino ("Sexologia"). Esta dimensão de Marta enquanto projeção ou exteriorização da alma de Ricardo está ligada à sua estranheza. Marta é real ou não? É apenas uma projeção? O que acontece no fim, quando desaparece? No seu ensaio sobre o estranho, Freud discute o caso de Der Sandmann, de E. T. A. Hoffmann. Baseando-se uma vez mais na sua conclusão de que o estranho é evocado, recorrentemente, pela emergência de medos ou desejos infantis que foram reprimidos, Freud argumenta que o motivo dos bonecos ou brinquedos animados enquanto elemento que desperta o estranho tem a sua origem nestes aspetos da experiência da criança. Mais exatamente, está relacionado não com um receio, mas com um desejo infantil: "children are not afraid of their dolls coming to life - they may even want them to" (141).

Ricardo define Marta como a sua criação e a sua vitória. Ela é, segundo o próprio, o produto do seu desejo de exteriorizar a sua alma (384). Simultaneamente, as palavras de Ricardo sugerem uma relação entre esta mesma criação e o processo de retorno de desejos infantis, comentado por Freud, quando

\footnotetext{
${ }^{9}$ A variedade de leituras, quer da novela quer deste episódio em particular, é eloquente quanto à eficácia da escrita de Sá-Carneiro para criar este "reading effect."
} 
afirma, num diálogo com Lúcio, que "toda a [sua] vida psicológica tem sido [...] a projecção dos [seus] pensamentos infantis" (322). Enquanto tal, a dimensão estranha de Marta emerge como uma manifestação ligada precisamente ao retorno deste aspeto da experiência infantil, utilizado na narrativa como forma de possibilitar a representação da relação de Lúcio e Ricardo a partir do modelo uranista. Pauline Palmer mostra a importância do estranho para a elaboração de várias formulações de desejos não normativos na literatura britânica contemporânea. Nicholas Royle já anteriormente identificara a dimensão queer do estranho, bem como a dimensão estranha do queer (43). A novela de SáCarneiro confirma a relevância do estranho para o imaginário da dissidência sexual no caso português, sublinhando a sua importância principalmente no contexto anterior à estabilização das identidades sexuais modernas.

Para Lúcio, tal como para o leitor, não é totalmente claro se Marta é uma figura real ou não. De forma semelhante, é impossível rejeitar completamente a ideia de que ela não é um duplo da americana que surge (e desaparece) na primeira parte da novela. Tal como a americana, Marta situa-se num espaço entre o real e o imaginário; entre Paris e Lisboa; entre amante fiel e adúltera; entre protagonista de uma relação heterossexual e mero veículo para o relacionamento entre Lúcio e Ricardo. Tal como a americana, ela desaparecerá no fim sem deixar rasto. Mais do que sublinhar o que a torna estranha, argumento que é fundamental nesta estranheza o facto de também ela, como já aconteceu com a americana, se caracterizar como alguém que vive num espaço-entre, em que sexualidade e fronteiras nacionais se estabelecem num contínuo que acaba por ser difícil de dissociar. Todos estes espaços-entre constituem o que podemos descrever, usando uma expressão de Bhabha, como uma intimidade intersticial que ocupa toda a novela e a define. Nas suas palavras, esta é "an intimacy that questions binary divisions through which such spheres of social experience are often opposed" (19). Este espaço-entre implica, em A confissão de Lúcio, não apenas questões de género e sexualidade, mas também o espaço real e as fronteiras geográficas cruzadas, quer pelas personagens de Sá-Carneiro quer por ele próprio. Marta, porém, ao contrário da americana, não tem uma origem nacional definida. ${ }^{10}$ Esta característica (in)definidora de Marta torna-se ainda mais

\footnotetext{
${ }^{10}$ Não há nenhuma indicação no texto sobre a origem nacional de Marta, apenas a afirmação que Ricardo talvez a trouxera de Paris: "Pois seria possível? Ricardo trouxera-a de Paris? Mas como não a conhecera eu, sendo assim. Acaso não o teria acompanhado à gare do Quai d'Orsay? Fora
} 
relevante quando observamos um dos aspetos da narrativa que até agora ainda não foi considerado pela crítica.

A acompanhar a relação tumultuosa entre Lúcio e Marta há um outro processo: o desfazer absoluto da pertença nacional de Lúcio que, apenas neste momento, assume uma identidade verdadeiramente cosmopolita-um cosmopolitismo de um espaço-entre, uma terra de ninguém. Depois de perceber, em Lisboa, a suposta traição de Marta, que estaria a ter um caso com o russo Warginski, Lúcio decide regressar a Paris. O relato desta descoberta segue o modelo de incerteza que domina grande parte das sensações levantadas por Marta-há uma dúvida que sempre permanece. Lúcio descreve assim a sua partida: "Dois dias depois, sem prevenir ninguém, sem escrever uma palavra a Ricardo, eu tive finalmente a coragem de partir" (372). O regresso à capital francesa é ao mesmo tempo uma fuga e uma vitória para Lúcio:

Durante a viagem [...] numa ânsia de chegar a Paris, as minhas torturas tinham-se enrubescido. Eu pensava que nunca chegaria a Paris, que era impossível haver triunfado, que sonhava com certeza - ou então que me prenderiam no caminho por engano; que me obrigariam a tornar a Lisboa, que vinham no meu encalço Marta, Ricardo, todos os meus amigos, todos os meus conhecidos [...]. (372)

Lúcio acaba mesmo por chegar a Paris, apesar do receio, mas o silêncio que antecede a partida continua na capital francesa. Durante os seis meses que passou em Paris após a sua chegada, Lúcio "[n]ão comprava jornais portugueses. Se vinha no Matin qualquer telegrama de Lisboa, não o lia; e assim, em verdade quase triunfara em esquecer-me de quem era... Entre a multidão cosmopolita, criava-me alguém sem pátria, sem amarras, sem raízes em todo o mundo" (376). O triunfo não é absoluto, embora este seja o momento em que Lúcio mais se aproxima da vitória que, nas suas palavras, consistiria em assumir uma identidade absolutamente desenraizada: “'Ah! Que venturoso eu fora se não tivesse nascido em parte nenhuma e entretanto existisse...' lembrei-me muita vez estranhamente,

verdade, não o acompanhara-lembrei-me de súbito" (347). Noutra passagem é afirmado por Lúcio que Marta não tem passado, o que implica também não ter uma origem nacional. 
nos meus passeios solitários pelos boulevards, pelas avenidas, pelas grandes praças..." (376). Esta perda de identidade é marcada por um lado pela recusa de Lúcio em estar com outros expatriados portugueses e, por outro, pela perda de interesse em ler jornais portugueses. ${ }^{11}$ De algum modo, a perda de identidade nacional do escritor Lúcio nas ruas de Paris neste momento da narrativa-ligado à recusa dos momentos de encontro dos sujeitos migrantes descritos por Bhabha no início deste artigo - é o momento verdadeiramente triunfal (para usar um termo caro tanto a Sá-Carneiro quanto a Pessoa) da novela, que, pelo menos por momentos, parece subordinar todos os outros que levaram até ele (desde a Orgia do fogo até à sua relação com Ricardo e Marta).

\section{Conclusão: performatividade e hibridismo}

A análise do modernismo português à luz da sua localização geográfica na periferia da Europa tem fornecido conclusões importantes e iluminado aspetos cruciais de textos como a "Ode marítima," de Álvaro de Campos (Beleza, "Orpheu cosmopolita"), e "Manucure," de Sá-Carneiro (Beleza, "Peripheral Desires"). A leitura da relevância da mobilidade transnacional de Sá-Carneiro que acabo de propor permite, por seu lado, oferecer uma perspetiva mais abrangente e complexa sobre as consequências estéticas da localização do modernismo português e dos processos de deslocação que o caracterizaram. Enquanto a dimensão periférica moldou certas dimensões da produção literária do modernismo português, especialmente o seu impulso cosmopolita, a experiência transnacional de autores como Sá-Carneiro permitiu não apenas o diálogo entre a geração do Orpheu e as inovações que ocorriam em Paris, mas também introduziu nas suas obras elementos ligados à experiência da mobilidade transnacional. Num momento em que os estudos sobre o modernismo cada vez mais mostram a importância de ler a produção cultural modernista para além de fronteiras nacionais, a obra de Sá-Carneiro emerge como um caso paradigmático de uma produção literária de caráter transnacional que importa revisitar enquanto tal, no contexto das literaturas e dos modernismos lusófonos. ${ }^{12}$

\footnotetext{
${ }^{11}$ Sá-Carneiro refere este sentimento na sua própria experiência quando escreve numa carta a Pessoa: "senti-me feliz: vida solitária, sem conhecer ninguém e sem acidentes, parada de alma e corpo" (Em ouro 355).

${ }^{12}$ Ver, por exemplo, Jay; Friedman.
} 
É precisamente tendo em mente o relevo do caso de Sá-Carneiro no contexto da dimensão transnacional e cosmopolita do modernismo português que, no pouco que resta deste artigo, pretendo propor uma leitura do poema “7” de SáCarneiro à luz da relevância do estranho e da sua relação com a experiência de mobilidade transnacional e da dissidência sexual que acabo de observar em $A$ confissão de Lúcio. Trata-se de uma leitura que, mais do que se propor como definitiva, tem como objetivo abrir novas formas de abordar a obra de SáCarneiro e o seu contributo para o cruzamento de fronteiras, quer nacionais, quer de género e sexualidade, que moldou o modernismo português e o tornou possível. O poema "7," com a data de fevereiro de 1914 e escrito em Lisboa, é extremamente curto e por isso o cito na sua totalidade: "Eu não sou eu nem sou o outro, / Sou qualquer coisa de intermédio: / Pilar da ponte de tédio / Que vai de mim para o Outro" (63).

O "outro" de que fala o poema, quando lido à luz dos argumentos que proponho neste artigo, deixa de ser um outro abstrato ou um mero motivo modernista. Pode ser lido, por um lado, como uma referência a um outro descoberto em nós. Como observa Kristeva em relação ao contributo da psicanálise para esta descoberta, o reconhecimento deste outro implica uma abertura radical ao estranho e a constituição de uma ética cosmopolita-uma ética que se estende, assim, da novela até ao poema e, argumento, até toda a obra de Sá-Carneiro, definindo-a. Por outro lado, logo a partir de A confissão de Lúcio, este outro surge como possuindo um referente real em termos de pertença geográfica, nacional, cultural, etc., como a americana, os convidados da sua festa, ou mesmo o poeta Zagoriansky. Quanto a Sá-Carneiro, ele próprio manifesta-se neste poema como a figura do intermédio/híbrido que se situa num espaço entre um eu fixo e estável (“mim”) e esse outro, precisamente o lugar onde Bhabha localiza a cultura - um espaço intersticial que se situa entre os discursos oficiais que procuram delimitar e fixar as culturas nacionais. Nas palavras de Bhabha, "[t]he interstitial passage between fixed identifications opens up the possibility of a cultural hybridity that entertains difference without an assumed or imposed hierarchy" (5). É este processo de identificação que emerge no poema e que permite argumentar que Sá-Carneiro, através do intermédio, constrói a sua identidade autoral a partir do hibridismo, de alguém que performativamente ocupa um espaço-entre - entre culturas e também entre identificações fixas nos campos do género e da sexualidade. Por outras palavras, apesar de ter escrito 
quase toda a sua obra em português, Sá-Carneiro é um autor que se situa num lugar performativo em que afirma a sua identidade para além das formas fixas de identidade e também das pertenças artísticas delimitadas por fronteiras nacionais.

Sem a experiência da mobilidade moderna em autores como Sá-Carneiro, o modernismo português teria sido radicalmente diferente. A mobilidade transnacional e a importância da dissidência sexual na produção de Sá-Carneiro levaram a uma total abertura ao outro que se mostra na sua obra e na forma como construiu a sua identidade, sublinhando a sua dimensão performativa, entre literatura, correspondência e o quotidiano de um escritor entre Lisboa e Paris. Este hibridismo modernista não pode ser dissociado do peso que a cultura francesa possuía no imaginário português da época e do carácter deficitário que Sá-Carneiro, tal como o seu amigo Pessoa, identificava na cultura e na produção artística nacional. Não pode ainda ser dissociado do contexto nacional do início do século, fortemente marcado por discursos nacionalistas. Enquanto o movimento da Renascença Portuguesa de Teixeira de Pascoaes procurava delimitar e fixar as supostas fronteiras da cultura nacional, Sá-Carneiro rejeitava formas estáveis de identidade e afirmava a sua pertença a um espaço-entre. Desta conjunção de contexto histórico e cultural surgiu assim um modernismo particularmente original, que se apresenta como uma ameaça tanto no campo da sexualidade como no da crítica literária, quebrando "the symmetry and duality of self/other, inside/outside" (Bhabha 165).

\section{Obras citadas}

Amaral, Ana Luísa. “'Durmo o crepúsculo’: lendo a poética de Mário de SáCarneiro a partir das teorias contemporâneas sobre as sexualidades." Subjetividades em devir: estudos de poesia moderna e contemporânea, edição de Célia Pedrosa e Ida Alves, 7Letras, 2008.

Arenas, Fernando. "Onde existir? A (im)possibilidade excessiva do desejo homoerótico na ficção de Mário de Sá-Carneiro." Metamorfoses, no. 6, 2005, pp. 159-68.

Beleza, Fernando. "Orpheu cosmopolita: políticas culturais e heterotopia sensacionista em 'Ode marítima,' de Álvaro de Campos.” Estranhar Pessoa, no. 2, 2015, pp. 30-56. 
—. "Peripheral Desires, Modernist Fantasies: Mário de Sá-Carneiro’s Queer Cosmopolitanism." Mário de Sá-Carneiro, A Cosmopolitan Modernist, edição de Fernando Beleza e Simon Park, Peter Lang, 2017, pp. 113-36.

- . "Sexologia, desejo e transgressão em A confissão de Lúcio, de Mário de SáCarneiro.” Paris, Mário de Sá-Carneiro et les autres, edição de Maria Araújo da Silva e Fernando Curopos, Éditions Hispaniques, 2017, pp. 37-54.

Bhabha, Homi K. "DisseminNation: Time, Narrative, and the Margins of the Modern Nation." The Location of Culture, Routledge, 1994, pp. 199-244.

Curopos, Fernando. "Mário de Sá-Carneiro and the Demons of Dance." Mário de Sá-Carneiro, A Cosmopolitan Modernist, edição de Fernando Beleza e Simon Park, Peter Lang, 2017, pp. 69-89.

Freud, Sigmund. The Uncanny. Tradução de David McLintock, Penguin, 2003.

Friedman, Susan. Planetary Modernism: Provocations of Modernity Across Time. Columbia UP, 2015.

Jay, Paul. Global Matters: The Transnational Turn in Literary Studies. Cornell UP, 2010.

Jentsch, Ernst. "Zur Psychologie des Unheimlichen." PsychiatrischNeurologische Wochenschrift, vol. 8, no. 22, 1906, pp. 195-98; 205-08.

Jones, Eleanor. "Undoing Anatomies: Performativity and Parody in Mário de SáCarneiro's A confissão de Lúcio.” Portuguese Studies, vol. 32, no.1, 2016, pp. 62-71.

Klobucka, Anna M. "Portugal's First Queer Novel: Rediscovering Visconde de Vila-Moura's Nova Safo (1912).” Journal of Lusophone Studies, vol. 4, no. 1, 2019, pp. 40-63.

Kristeva, Julia. Estrangeiros para nós mesmos. Tradução de Maria Carlota Carvalho Gomes, Rocco, 1994.

Martins, Fernando Cabral. O modernismo em Mário de Sá-Carneiro. Estampa, 1997.

Palmer, Paulina. The Queer Uncanny: New Perspectives on the Gothic. U of Wales P, 2012.

Park, Simon. "'Eu serei então um bárbaro?': Art, Dance, and Artistic Belonging in Mário de Sá-Carneiro." Mário de Sá-Carneiro, A Cosmopolitan Modernist, edição de Fernando Beleza e Simon Park, Peter Lang, 2017, pp. 91-112. 
Pazos-Alonso, Claudia. "Displacement and Condensation: A Freudian Analysis of A confissão de Lúcio.” Journal of Romance Studies, vol. 11, no. 3, 2011, pp. 65-76.

Pitta, Eduardo. Fractura: a condição homossexual na literatura portuguesa contemporânea. Angelus Novus, 2003.

Royle, Nicholas. The Uncanny. Manchester UP, 2003.

Sá-Carneiro, Mário de. Em ouro e alma: correspondência com Fernando Pessoa, edição de Ricardo Vasconcelos e Jerónimo Pizarro. Tinta da China, 2015.

—. Verso e prosa. Assírio \& Alvim, 2010.

Saunders, Max. Self Impression: Life-Writing, Autobiografiction, and the Forms of Modern Literature. Oxford UP, 2012.

Vasconcelos, Ricardo. "Painting the Nails with a Parisian Polish: Modern Dissemination and Central Redemption in the Poetry of Mário de SáCarneiro.” Pessoa Plural, no. 4, 2013, pp. 129-51. 